\title{
Erratum to: Differential intratumoral distributions of CD8 and CD163 immune cells as prognostic biomarkers in breast cancer
}

Sotirios P. Fortis ${ }^{1+}$, Michael Sofopoulos ${ }^{2+}$, Nectaria N. Sotiriadou ${ }^{2}$, Christoforos Haritos ${ }^{1}$, Christoforos K. Vaxevanis ${ }^{1}$, Eleftheria A. Anastasopoulou', Nicole Janssen ${ }^{3}$, Niki Arnogiannaki ${ }^{2}$, Alexandros Ardavanis ${ }^{4}$, Graham Pawelec ${ }^{3}$, Sonia A. Perez ${ }^{1 * \dagger}$ and Constantin N. Baxevanis ${ }^{1 \dagger}$

\section{Erratum}

After publication of this article [1], it was noticed that Table 3 contained errors introduced during the production process. The corrected Table 3 can be seen below and the original article has been updated to correct the errors.

\footnotetext{
Author details

${ }^{1}$ Cancer Immunology and Immunotherapy Center, Saint Savas Cancer Hospital, Athens, Greece. ${ }^{2}$ Pathology Department, Saint Savas Cancer Hospital, Athens, Greece. ${ }^{3}$ Center for Medical Research, Eberhard-Karls Universität, Tübingen, Germany. ${ }^{4}$ First Medical Oncology Clinic, Saint Savas Cancer Hospital, Athens, Greece.
}

Received: 15 May 2017 Accepted: 15 May 2017

Published online: 30 May 2017

\section{Reference}

1. Fortis, S. P., Sofopoulos, M., Sotiriadou, N. N., Haritos, C., Vaxevanis, C. K., Anastasopoulou, E. A., ... Baxevanis, C. N. Differential intratumoral distributions of CD8 and CD163 immune cells as prognostic biomarkers in breast cancer. J Immunother Cancer. 2017, 5, 39. http://doi.org/10.1186/s40425-017-0240-7.

\footnotetext{
*Correspondence: perez@ciic.gr

${ }^{\dagger}$ Equal contributors

${ }^{1}$ Cancer Immunology and Immunotherapy Center, Saint Savas Cancer

Hospital, Athens, Greece
} 
Table 3 Multivariate Cox proportional hazard analysis for DFS and OS of patients with non-mesastatic invasive breast cancer

\begin{tabular}{|c|c|c|c|c|c|c|}
\hline & \multicolumn{3}{|l|}{ DFS } & \multicolumn{3}{|l|}{ OS } \\
\hline & Hazard Ratio & $P$ & 95.0\% Cl for HR (range) & Hazard Ratio & $P$ & 95.0\% Cl for HR (range) \\
\hline TNM stage $^{b}$ & 2.180 & 0.009 & $1.219-3.898$ & 3.937 & 0.006 & $1.494-10.371$ \\
\hline Signatures ${ }^{b}$ & 1.560 & 0.138 & $0.866-2.810$ & 2.085 & 0.091 & $0.889-4.890$ \\
\hline \multicolumn{7}{|c|}{ Model before stepwise selection } \\
\hline $\mathrm{Age}^{\mathrm{a}}$ & 1.031 & 0.948 & $0.411-2.589$ & 4.391 & 0.188 & $0.486-39.703$ \\
\hline T status $^{\mathrm{b}}$ & 2.613 & 0.010 & $1.255-5.439$ & 3.679 & 0.028 & $1.148-11.793$ \\
\hline$N$ stage $^{b}$ & 1.222 & 0.512 & $0.671-2.225$ & 1.125 & 0.815 & $0.420-3.010$ \\
\hline Grade $^{b}$ & 1.142 & 0.750 & $0.504-2.585$ & 4.189 & 0.027 & $1.180-14.867$ \\
\hline HER-2/neu & 0.928 & 0.884 & $0.342-2.520$ & 0.066 & 0.016 & $0.007-0.066$ \\
\hline Hormone Receptors & 0.277 & 0.004 & $0.277-0.669$ & 0.618 & 0.007 & $0.046-0.621$ \\
\hline Signatures ${ }^{b}$ & 2.063 & 0.041 & $1.031-4.126$ & 4.850 & 0.014 & $1.374-17.122$ \\
\hline \multicolumn{7}{|c|}{ Model after stepwise selection } \\
\hline T status $^{\mathrm{b}}$ & 2.999 & 0.001 & $1.602-5.615$ & 3.522 & 0.005 & $1.477-8.398$ \\
\hline Hormone Receptors & 0.269 & 0.002 & $0.116-0.621$ & 0.231 & 0.014 & $0.072-0.742$ \\
\hline Signatures $^{\mathrm{b}}$ & 2.146 & 0.027 & $1.091-4.219$ & 4.273 & 0.006 & $1.521-11.999$ \\
\hline
\end{tabular}

${ }^{\mathrm{a}}$ Age under 50 and over 50 years old

${ }^{b}$ All categorical covariates were transformed into numeric codes as follows: T status (T1; 1, T2; 2, T3; 3), N stage (NO; 0, N1; 1, N2; 2, N3; 3), Grade (G1; 1, G2; 2, G3; 3), Signatures (FCIS; 1, Rest; 2, UCIS; 3) TNM stage (I; 1, II; 2, III; 3) 